Revista Colombiana de Obstetricia y Ginecología Vol. 56 No.1 • 2005 • (35-45)

Artículo de REFLEXIón

\title{
ALGUNAS CONSIDERACIONES ANTROPOLÓGICAS Y RELIGIOSAS ALREDEDOR DE LA MENSTRUACIÓN
}

\author{
Some anthropological and religious considerations concerning \\ menstruation
}

Miguel Ángel Alarcón-Nivia, M.D*

Recibido: octubre 8/2004 - Revisado: enero 27/2005 - Aceptado: febrero 8/2005

\section{RESUIMEN}

Este trabajo comprende una revisión de los nombres populares que se le dan a la menstruación en Colombia, las creencias indígenas alrededor del tema en diferentes partes del mundo, las precauciones y prohibiciones qu e se tienen respecto a las mujeres menstruantes desde la mira de algunas religiones. Se presentan también algunas explicaciones sobre las causas de la menstruación, según filósofos de la antigüedad y pensadores modernos.

Palabras clave: menstruación, antropología, religión, historia, Islam, biblia.

\section{SUIMMARY}

This article mentions popular names referring to menstruation in Colombia, indigenous people's beliefs in different parts of the world, precautions and prohibitions from some religions points of view and explanations given by some ancient philosophers and modern thinkers regarding menstruation.

Key words: menstruation, anthropology, religion, history, Islam, Bible.

\footnotetext{
* Profesor del Departamento de Ginecoobstetricia, Universidad Industrial de
} Santander. Correo electrónico: alarcon@intercable.net.co

\section{INTRODUICCIÓN}

Este es un artículo de revisión de la percepción del fenómeno de la menstruación, vista por los indígenas de diferentes partes del planeta, por la población general, por los textos sagrados de diferentes religiones y por diferentes pensadores de la antigüedad y de la era moderna.

Decía la escritora y filósofa francesa Simone de Beauvoir en "El segundo sexo", libro que se ha considerado líder del feminismo, ${ }^{1}$ que la sangre menstrual representa la esencia de la feminidad. Este evento, que es completamente normal y fisiológico ha sido percibido desde épocas pretéritas como un fenómeno misterioso, alrededor del cual se han tejido numerosos mitos y tabús ${ }^{2,3}$ de los cuales los más frecuentes han sido aquellos que requieren aislamiento de la mujer menstruante, los que prohíben las relaciones sexuales en este período, los que prohíben preparar alimentos, sobre todo para sus parejas, los que consideran la sangre menstrual como un líquido peligroso o venenoso y los que le confieren poderes mágicos. En algunas culturas (cristianos ortodoxos) las mujeres menstruantes están excluidas de la comunión.

\section{NOMENCLATURA DE LA PALABRA}

El término menstruación viene del latín menstruum, que a su vez viene de menstruus, que significa mensual. 
El equivalente en griego para la palabra mensual es menós, por lo que algunos términos que se refieren a la menstruación llevan este prefijo: menarquia, menorragia, menometrorragia, etc. ${ }^{4,5}$

\section{La menstruación en el argot popular}

En nuestro país las palabras coloquiales de uso diario para referirse a la menstruación fueron recogidas por Luis Flórez, quien las publicó en uno de los documentos del Instituto Caro y Cuervo. ${ }^{6}$ El capítulo dedicado a esta función del aparato genital femenino hace referencia a los siguientes términos: la colorada, el consuelo, la cortada del dedo, la corriente, la cosa, la costumbre, la mensual, el chorrito, la chorriada, estar chorriando, estar chorriando la piña, el derrame, la diecinueve y doce, estar enferma, estar entiempada, tener la enfermedad del mes, estar a fin de mes, tener el flujo, tener la hemorragia, estar con la luna, estar con la luna brava, estar de luto, estar mala, tener las lluvias, tener el mal de las mujeres, estar con la mensualidad, estar con el mes, tener visita, estar con la mestruel, estar con la demostración, estar con la administración, estar con la postración, estar morajiá, estar pagando arriendo, estar con Pachito, estar con el Chapulín Colorado, estar con el período, estar picada del murciélago, tener la regla, estar con el reglamento, estar con esa bicha, estar con esa joda, estar con el reglero, estar con el arreglamiento, estar en remate de mes, estar con la roja, estar en la semana, estar con la soltura, estar con el treinta y jeo, estar con la treinta y una, estar con la veintiuna, estar en esos días. El autor de las presentes notas ha agregado algunos términos propios de Santander, Colombia.

\section{PERSPECTIVA ANTROPOLÓGICA}

En las culturas indígenas de diferentes partes del mundo se ha creído que el fluido menstrual fue causado por primera vez por la mordedura de un animal en la región genital de la mujer, que originó los seres humanos. ${ }^{7}$ Los animales comprometidos han sido un lagarto, un oso, un cocodrilo, una serpiente, un pájaro (...); de todos, la serpiente ha sido la más frecuentemente implicada. Entre las tribus de México, Brasil, Norteamérica y Bolivia, este animal ha jugado un papel central como causante de la menstruación, como violador de las adolescentes solitarias o como terapia para las mujeres que entran en amenorrea. ${ }^{8}$

Entre las tribus del sur de Australia se creía que la menstruación era causada por los arañazos en la vagina de un animal que se movía con los cambios de la luna. Según los indios Monominee, que habitaban el territorio donde actualmente queda Michigan, Estados Unidos, la menstruación era el resultado de la experiencia de Manabush , quien sorprendió a su abuela haciendo el amor con un oso. Manabush mató al oso y le ofreció parte de la carne. Ella se rehusó a comerla aduciendo que este animal era su esposo. El le arrojó un coágulo de sangre que le golpeó en el vientre. Ella se enfureció y le dijo que a causa de su falta había dado nacimiento a un mal que las mujeres sufrirían cada fin de luna, el cual se mostraría con coágulos como el de esa ofensa. ${ }^{3}$

Entre la comunidad hindú de los Manu, se creía que un hombre que tuviera relaciones con una mujer menstruante perdía su fuerza física, su energía de vivir, su sabiduría y su cordura. En la tribu hindú de los Bhinyan se construye una puerta en la casa para uso exclusivo de las mujeres menstruantes. ${ }^{9}$

Entre los indígenas Finno Ugric de Kenia, en el África, no era permitido que estas mujeres mirasen al cielo pues podían atraer tormentas.En algunas tribus de Angola se pinta la cara o el cuerpo de la mujer para identificar su condición en esos días. En parte del Congo no pueden cocinar esos días si los alimentos van a ser consumidos por hombres. ${ }^{10}$

Las tribus de Nueva Zelanda creían que la menstruación era el equivalente a un aborto de seres humanos que tenían dificultades para formarse en el vientre materno. ${ }^{10}$

En muchas tribus indígenas, especialmente del Brasil y de la Guayana Francesa, se maltrataba a las adolescentes hasta el desmayo cuando menstruaban en abundancia, para extraerles los demonios que les causaban ese trastorno. En el plano cognitivo encon- 
tramos que la vida ritual de los Kuna, que habitan territorios de Colombia y Panamá, gira en torno a la mujer, y más concretamente en su capacidad de esposa y madre, por lo cual los ritos asociados a la primera menstruación cobran una extremada importancia en su cultura. ${ }^{11}$

La tribu U 'Wa, de la familia Tunebo, que habita en la Sierra Nevada de Chita o Cocuy (alrededor del lago Bekana, al que consideran como el centro del mundo), impone a las jóvenes adolescentes de esta comunidad un sombrero llamado Kókora, hecho con hojas de rascadera, el día que les llega la menstruación. El sombrero de Kókora, que se lleva por lo menos un año, debe protegerla de los trastornos de la menstruación, del embarazo y ayudarla en la vida cotidiana. Durante el tiempo que la muchacha debe llevar la Kókora deben observar normas muy estrictas. Entre éstas se encuentran el bañarse todos los días a las 4 de la mañana y no dejar ver su cabellera por nadie. "Antiguamente el Kókora se llevaba durante cuatro años. Actualmente solamente la llevan más o menos durante un año. Este rito también se llama 'rito de paso' y lo deben celebrar con la finalidad de prevenirle enfermedades a la muchacha en la segunda etapa de la vida y evitar que se presenten problemas durante las menstruaciones, el embarazo, el parto y la vida cotidiana". ${ }^{12}$

Para quitar la Kókora existe otra ceremonia: cuando una muchacha ya ha cumplido, según el jefe Uejená y según sus padres, con el tiempo previsto, se prepara una fiesta a la cual se invita mucha gente pues se ofrece un banquete con bastante carne de monte y plátano. Cuando le quitan la Kókora su pelo debe aparecer largo y liso; su rostro debe aparecer rosado y elegante.

Entre la cultura Tairona, en la Sierra Nevada de Santa Marta, la ceremonia de iniciación, que es propia de la llegada de la primera menstruación, se celebra de manera sencilla, con un ayuno que les da la bienvenida a la vida fértil. Entre los Kuna-Tules de los golfos de Urabá y de San Blas en Colombia y Panamá, respectivamente, las adolescentes que tienen su menarquia son celebradas con numerosos ritos y fiestas que las inician en su vida fértil, pero también en su capacidad de ser esposa, rol muy importante en la tribu, pues ellas ejecutan los trabajos más difíciles, que les disminuyen la longevidad respecto a los hombres. Entre los indígenas de las etnias emberá, emberá-chamí y waunaan, en los afluentes del río Atrato al suroccidente de Colombia, es frecuente el uso de adornos de plata en la fiesta de iniciación de las mujeres. La niña que llega a su primera menstruación tiene su cuerpo profusamente pintado, viste una paruma (falda típica) de tela roja y lleva una corona de monedas en la cabeza, lo cual se complementa con flores, perfumes y una tela roja que le oculta el rostro. ${ }^{11}$

\section{PUIRIFICACIÓN Y SECLUISIÓN}

Según diferentes creencias, la manera de purificarse de los males que trae consigo la menstruación se logra principalmente con un baño ritual o mediante el baño repetido tres veces durante el día. En algunas tribus australianas por el contrario, se aísla a las mujeres del mar o de los ríos para no echar a perder la pesca. En algunas tribus se acostumbra hacer una danza cuando la mayoría de las mujeres han terminado el ciclo para mostrar el regocijo por la recuperación de su pureza. Antiguamente muchas tribus indígenas construían una choza llamada casa de seclusión, ${ }^{13}$ casa de aislamiento o casa menstrual. La palabra seclusión hace referencia al aislamiento a que eran sometidas las adolescentes durante este período de su vida. En Colombia tal vez el mejor ejemplo de estas construcciones son las chozas de la comunidad Wayú (habitantes del territorio comprendido entre los ríos Ranchería de la Guajira, y el río Limón al noroeste de Venezuela), que sirven para separar a las jóvenes que entran en la adolescencia luego de la menarquia.

El editorialista de Etnias de Colombia ${ }^{14}$ cita el siguiente texto de Vergara, escrito en 1997, sobre los indígenas Wayú: “(...) No se destaca la pubertad en los varones, pero las niñas están sometidas a un severo rito de paso. Cuando la muchacha empieza a menstruar, es sometida a un período 
de reclusión, al término del cual se ha convertido en mujer equipada para casarse. Durante el inicio de esta reclusión, la joven es completa o parcialmente rapada y luego instalada en una hamaca colgada cerca del techo de la casa. Durante los días siguientes es cuidada con alimentos vegetales especiales, llamados jaguapi, y observa una dieta rigurosa. En ese tiempo la bañan con frecuencia y la instruyen en las tareas femeninas, tejido, hilado, le imparten conocimientos sobre los procesos tradicionales de control natal, embarazo y quizás algunas técnicas eróticas". ${ }^{14}$

Durante su período de seclusión (que equivale en cierta forma a un período de reclusión), se las prepara en los oficios domésticos y en el arte de atender al marido, cuando le llegue la hora de hacerlo. ${ }^{15}$

\section{LA MENSTRUACIÓN VISTA POR DIFERENTES RELIGIONES}

(El autor se disculpa si su interpretación, siempre respetuosa, de la sagrada Biblia, del Corán y de la Torah en los aspectos aquí mencionados, pueda herir la susceptibilidad de alguno de sus lectores. Se citan textualmente las frases de cada uno de los libros citados).

\section{Religión musulmana}

Las mujeres musulmanas están exentas de ayuno durante los días de la menstruación en el mes del Ramadán. Durante este mes ninguna persona debe ingerir alimentos entre las 7 de la mañana y las 7 de la noche. Se exceptúan los niños, los ancianos y las mujeres menstruantes. ${ }^{16}$

Aunque el libro sagrado llamado Sahib Bukhari hace mención de la menstruación (vol. 1, libro 6), es el Corán (Qu'aran), ${ }^{17}$ el libro sagrado de los musulmanes, el que tiene preceptos similares a la Biblia católica, respecto a las relaciones sexuales durante la menstruación a la cual considera casi como una enfermedad: ${ }^{18}$

Verso 2.222: "Te preguntan acerca de la menstruación. Dí: "Es un mal imanteneos pues aparte de las mujeres durante la menstruación y no os acerquéis a ellas hasta que se hayan purificado!. Y cuando se hayan purificado, id a ellas como Alá os lo ha ordenado“. Quien teme a Alá, él le facilita sus cosas".

El Corán hace referencia a los períodos de amenorrea de la siguiente forma:

Verso 65.4: "Para aquellas de vuestras mujeres que ya no esperan tener la menstruación, si tenéis duda, el tiempo de espera será de tres meses. Lo mismo para las impúberes. Para las embarazadas el período de espera terminará cuando den a luz. Quien teme a Alá, él le facilita sus cosas"

\section{El Purdah}

Por obediencia de los preceptos del Purdah, un ritual religioso-social de muchas comunidades musulmanas, hindúes y del medio oriente, las mujeres son literalmente aisladas del resto del público y aún dentro de su familia, pues las casas tienen muros, ventanas mínimas, velos o láminas que las separan en ambientes individuales.

Cuando salen a la calle deben usar prendas de vestir que les cubre el cuerpo de los pies a la cabeza, unas veces quedan sólo visibles los ojos, otras veces la cara, también se aíslan con un velo (como ocurre con la Burka). El Purdah se originó probablemente en Persia y en la antigua Babilonia y se extendió por el medio oriente. Los musulmanes lo incorporaron a su religión hacia el siglo VII a.c. El profeta Muhammad (Mahoma), le dió énfasis como parte de la expresión de fe entre las mujeres, y también como expresión de respeto, de honor y dignidad. Una manera de conservar la cohesión cultural de los musulmanes hindúes durante la invasión inglesa, fue la observación rigurosa de la indumentaria femenina y de los rituales propios del Purdah. Con el tiempo su cumplimiento tomó fuerza de ley, asociada a castigos físicos y la muerte para quienes no lo cumplieran. ${ }^{19}$

Hacia los 13 años de edad, época de la primera menstruación, la joven debe iniciarse en el Purdah, debe salir a la calle con una burka de color violáceo, que indica su condición de soltera. ${ }^{20,21}$ 


\section{Religión católica}

El Levítico, o libro de la Biblia de la Tribu de Leví, escogida por Dios para el derecho de ejercer el sacerdocio, dedica el capítulo XV a la manera de limpiarse de dos impurezas del cuerpo: la gonorrea y la menstruación. ${ }^{21}$

En los numerales 19 al 33 considera el estado menstrual como una inmundicia capaz de transmitir esta condición a cualquier objeto o persona que se ponga en contacto físico con la mujer en esos días. Tan despreciable es padecer una gonorrea como tener relaciones sexuales durante los días de la menstruación. Tener la menstruación convierte a la mujer en una persona inmunda, por esta razón puede transmitir esta especie de desgracia a todo aquello que la rodea.

Veamos ahora los preceptos del libro Levítico ${ }^{22}$ que hacen referencia directa a la prohibición de tener relaciones sexuales durante una semana:

- XV, 19. "La mujer que padece la incomodidad ordinaria del mes, estará separada por siete días.

- XV, 24. Si el marido inadvertidamente se junta con ella en el tiempo de la sangre menstrual, quedará inmundo siete días, y toda la cama en que durmiere quedará inmunda".

Todo objeto o persona que se pone en contacto físico con la mujer que menstrúa, se contagia de la inmundicia:

- XV, 20. "Cualquiera que tocare a la mujer que padece la incomodidad ordinaria del mes, quedará inmundo hasta la tarde.

- XV, 26. Toda cama en que durmiere y todo mueble sobre el cual se sentare, quedará inmundo".

Los numerales 21, 22, 27, 29 y 30 también mencionan como se contagian de inmundicia la cama y los demás muebles que utilice la mujer que menstrúa y la manera de liberarse su esposo o familia de esa condición, mediante un baño corporal, lavado de sus ropas y sacrificio de dos aves:

- XV, 21. "Aquello sobre que durmiere o se sentare en los días de su separación, quedará inmundo.

- XV, 22. Quien tocare su lecho, lavará sus vestidos; y él mismo, después de lavarse en agua, quedará inmundo hasta la tarde.

- XV, 27. Cualquiera que tocare estas cosas, lavará sus vestidos; y él mismo, después de lavarse en agua, quedará inmundo hasta la tarde.

- XV, 29. Y el octavo día ofrecerá por sí al sacerdote dos tórtolas o dos pichones a la entrada del tabernáculo del testimonio.

- XV, 30. de los cuales el sacerdote sacrificará uno por el pecado y otro en holocausto y hará oración por ella delante del Señor para purificarla de su inmundicia."

Los evangelistas percibieron que la duración excesiva de la menstruación era equivalente a una enfermedad, y como tal la considera sabiamente el Levítico:

- XV, 25. "La mujer que padece flujo de sangre muchos días fuera del curso ordinario, o aquella que después de pasado el período menstrual prosigue con el flujo, mientras le sigue esta enfermedad quedará inmunda, como si estuviere en el período de su menstruo".

El Levítico muestra semejanzas entre el hombre que sufre de gonorrea y el hombre que ha tenido relaciones sexuales con una mujer durante la menstruación:

- XV, 32. "Esta es la ley del que padece gonorrea y del que se mancha uniéndose con mujer.

- XV, 33. Y de la mujer que se separa en sus períodos menstruales, o que padece flujo continuado de sangre, y del hombre que durmiere con ella". ${ }^{23}$

La Torah legisla sobre el Niddah, en la religión judaica. El término Niddah tiene dos acepciones: a. Es la ley de la separación del esposo durante la menstruación (en cuyo caso también se llama taharat ha-mishpachah). Etimológicamente en hebreo Niddah significa "retirada".

b. A las mujeres menstruantes se las llama Niddah. La Torah, libro sagrado de los judíos tiene preceptos muy cuidadosos sobre el Niddah: allí están contempladas las normas de la separación durante los días de la menstruación. Para evitar un contacto corporal accidental o un coito durante la menstruación, la esposa 
debe dormir en un cuarto aparte o al menos en otra cama, desde los días previos a la fecha calculada para que le llegue la regla. Esta es la llamada "abstinencia anticipatoria”. En esos días ella puede permitir caricias íntimas, que suspenderá cuando se convierta en Niddah (mujer menstruante). Dice la Torah:

- Ezequiel 18:5, 6. "Si un hombre es virtuoso y cumple con actos de justicia y caridad... él no profanará a la mujer de su vecino ni se acercará a una mujer Niddah".

- Levítico 15:19. "Cuando una mujer tuviere un flujo de sangre que proviene de la sangre que circula por su cuerpo, ella será 'Niddah' durante siete días."

- Levítico 18:19. “Tu no deberás (incluso) acercarte para poner al descubierto la desnudez de una mujer que es 'impura' por su condición de "Niddah".

- Levítico 20:18. "Si un hombre se acostare con una mujer que es 'Niddah' y descubre su desnudez, ambos serán aislados de su comunidad".

La separación termina en la tarde del séptimo día de limpieza, por lo cual dura en total unos 12 días. Al final de la separación la esposa hace un baño ritual (mikvah) en una piscina, si dispone de ella, o en una ducha. El significado es enteramente espiritual, por lo cual deberá realizar el mikvah sólo cuando se ha bañado de las impurezas físicas.

Los rabinos enfatizan en las ventajas del Niddah: dan fortaleza espiritual a los esposos, fortalecen el amor y el deseo entre ellos, les evita enfermedades genitales, etc. El Niddah termina con el mikvah.

Las normas religiosas del judaísmo (el libro escrito -Torah-y su forma oral -el Talmud-) legislan también sobre la higiene íntima de las mujeres durante la menstruación. Ninguna mujer podrá casarse durante el Niddah. ${ }^{24-31}$

\section{MITOS Y TABÚES ALREDEDOR DE LA MENSTRUACIÓN}

El historiador romano Caius Plinius Cecilius Secundus (años 29-72), llamado Plinio el Viejo (o el Naturalista), recogió en el siglo I de nuestra era las creencias que se transmitían oralmente de generación en generación en su enciclopedia de 37 libros llamada "Historia Natural". En el libro VII, capítulo 13, se hace referencia a la manera como la gente percibía la menstruación como una desgracia personal y colectiva: "tener relaciones sexuales con una mujer durante la menstruación hace que el vino se convierta en vinagre, las semillas que ella toca se hacen estériles, las plantas se marchitan, las frutas caen de los árboles antes de madurar, las yeguas abortan a sus crías. Todo esto se hace peor cuando la mujer ha perdido la virginidad durante la menstruación. En el Libro XXVIII capítulo 23, continúa:“... los hombres serán abandonados por sus esposas si tienen relaciones con una mujer menstruando... se quemarán ellos mismos." 32-34

Plinio registró la creencia popular de que la menstruación era el material del cual se formaban los fetos gracias a la semilla masculina (semen), que transformaba esa materia en un cuerpo humano de manera similar como la levadura comprimida le da forma y volumen a los ponqués. ${ }^{32-34}$

En la India del siglo XVIII se creía que la entrada del semen por la vagina antes de la menarquia prevenía la muerte fetal in útero, por esto se escogía desde edad muy temprana al esposo de la prepúber para que su primera relación ocurriera “antes que la sangre corriera por primera vez". No hacerlo de esta forma equivalía casi a un crimen. ${ }^{10}$ Los antiguos judíos no permitían que las mujeres menstruantes fueran al culto religioso, ni podían estrechar la mano del rabino, o tocar objetos sagrados. El marido no debía alcanzarle nada mano a mano, pues quedaba contaminado. ${ }^{35}$

Gran parte de las creencias antiquísimas se mantienen aún hoy en día en todas las culturas del mundo. Un grupo de señoras inglesas cree que la leche manipulada por una mujer durante el período menstrual, no puede convertirse en mantequilla. En Galela no se les permite entrar a los campos sembrados con tabaco. En Sumatra tienen prohibido 
entrar en los sembrados de arroz. En Saigón no se les permite trabajar en la elaboración del opio para evitar que este se ponga amargo. En la tribu Kafir del sur del África creen que si una mujer bebe leche, la vaca puede caer muerta. En algunas regiones de Francia creen que si entran en una fábrica de azúcar pueden echar a perder este producto. ${ }^{36}$

En China y Japón se recomienda a las mujeres no consumir Fucus vesiculosus. El Dr. CK Skibola investigó este fenómeno y publicó un artículo que parece comprobar que el consumo de esta planta prolonga los días de la menstruación. ${ }^{37}$

\section{¿QUÉ ES LA SANGRE MENSTRUAL?, ¿POR QUÉ O PARA QUÉ LAS MUJERES MENSTRÚAN?}

\section{Respuesta de los pensadores a través de los tiempos}

Sobre la presencia de este fenómeno fisiológico han opinado a través de la historia todo tipo de pensadores: filósofos, líderes religiosos, fisiólogos, biólogos, antropólogos, ginecólogos, etc.

Pitágoras, el famoso matemático, filósofo y político griego del siglo V a.c., decía en su escuela de Crotona, que las leyes de la naturaleza y la realidad inmanente de las cosas tienen una estrecha relación con los aspectos divinos. En cierta forma mezclaba la "ciencia" con la religión de su época. Opinaba que la sangre menstrual era la espuma de la sangre, que contenía la superfluidez de las enfermedades. La menstruación eliminaba algunas enfermedades. ${ }^{38}$

Hipócrates (460-377 a.c.), el más famoso médico de la antigüedad, nacido en la isla de Cos, llamado "El padre de la medicina", hablaba de la menstruación como un proceso normal y mencionaba sus trastornos como parte de las enfermedades sagradas llamadas Morbo Sacro. ${ }^{39}$

En el siglo IV el macedonio Aristóteles (384322 a.c.), uno de los más grandes pensadores que ha tenido la humanidad, explicaba en su Historia Animalium que la sangre menstrual era el excedente que se eliminaba de la sangre corporal y que ade- más servía como alimento para la formación del feto que se había iniciado por acción del fluido genital masculino. Dejaba en claro que este fenómeno femenino cesaba alrededor de los 50 años. Aristóteles decía que la sangre menstrual proveía la materia prima para el desarrollo del feto después que se ha formado por acción del esperma. Por aquella época se consideraba que la vida sexual durante la menstruación traía desgracias para la región: hacía que las cosechas se perdieran, que los frutos cayeran de los árboles antes de tiempo, que el hierro se oxidara y que el cobre se pusiera negro. ${ }^{40}$

Claudio Galeno, el más famoso médico de la antigüedad después de Hipócrates, en el siglo II, explicaba que la menstruación es una forma de eliminar la llamada "sangre superflua". ${ }^{41}$

Philippus Paracelsus, médico suizo, famoso en toda Europa por sus publicaciones en astrología, alquimia, química, medicina y teología, a mediados del siglo XVI, opinaba que la menstruación era una forma de depuración y purificación del cuerpo.

Mustitamus en su libro Diseases of the Women (1793), dice que el origen de la menstruación comenzó cuando Eva comió de la fruta prohibida y percibió un deseo sexual; por esto le ofreció a Adán compartir este alimento afrodisíaco. Y así ocurrió su primera relación sexual. Las futuras generaciones se mancharon de este pecado y el Eterno le envió la menstruación a Eva como un castigo para recordarle el Fiddei commissum (la obligación de transmitirle esta aflicción a sus sucesoras). ${ }^{42}$

Los Levitas, pobladores de North Queensland en Australia, creían que la menstruación era la manera de eliminar los tóxicos y sustancias desechables de la sangre. Otros habitantes de la región opinaban que la sangre provenía de una ruptura episódica del hígado. Los habitantes de la isla Sándwich (posesión inglesa cercana a las islas Malvinas o Falkland islands, frente a Argentina, en el Océano Atlántico), achacaban el sangrado a una secuela de la vida sexual. ${ }^{43}$

En el año 1846 Charles Darwin, opinaba que 
si este fenómeno ha sobrevivido a la selección natural, debe ser útil para algo, o al menos no hace daño.

En el año 1910 Marshall mencionaba la similitud entre la menstruación femenina y el proestro de algunas hembras mamíferas como las perras. Señala que el sangrado pone en alerta a los machos de su disponibilidad para la fecundación y les estimula el deseo sexual. ${ }^{44}$

Hacia 1930 Ruddock explicaba que el fluido menstrual eliminaba los embriones que no se implantan. Así mismo planteó la hipótesis de que el fluido menstrual provee satisfacción sexual a las mujeres sin que pierdan la virginidad. El mismo año aparece un documento de la Vitalogy Association de Chicago, en el cual los autores opinaban que la menstruación era la forma de deshacerse de los embriones que no se implantan. ${ }^{44}$

En 1985, Fox opinaba que la menstruación era una forma eficaz de favorecer otra ovulación y una nueva oportunidad de quedar embarazada. ${ }^{44}$

En 1993 Profet propuso la hipótesis de que la menstruación remueve los patógenos que entran con el coito. ${ }^{44}$

En 1995 la American Antropological Society califica la menstruación como la potencia sexual femenina, mediante la cual demuestra su competencia reproductiva. El mismo año Clarke, con base en el conocimiento epidemiológico de que la principal causa de aborto espontáneo es el conjunto de anormalidades cromosómicas que reconoce el útero, declara que la menstruación tiene como función importante eliminar los embriones reconocidos como defectuosos. ${ }^{45}$

En 1996 Strassman de la Universidad de Michigan, escribe que la menstruación es un mecanismo ahorrador de la energía que se gastaría si el endometrio se mantuviera constantemente en óptimas condiciones de recibir el blastocisto. El ciclo menstrual hace que esas condiciones óptimas para recibir el óvulo fecundado sólo ocupen alrededor de cinco días cada mes. Pasando este concepto a números, de los 36 años de vida fértil (entre los 13 y los 49 años de edad) transcurren 12.960 días. Asumiendo que sólo 5 días de cada mes son fértiles, la cifra se reduce a 2.160 días de preparación energética para iniciar la gestación. En otras palabras, el ciclo menstrual ahorra el 83,4\% de ese gasto. ${ }^{5}$

A través de varios artículos científicos el Dr. CA Finn, veterinario de la Universidad de Liverpool, Inglaterra, da una explicación, algo compleja, de que la menstruación es una adaptación de 2.500 años a múltiples funciones reproductivas en secuencia. ${ }^{45-47}$

\section{¿Contiene tóxicos la sangre menstrual?}

Desde tiempos inmemoriales mucha gente ha querido explicarse qué es la menstruación. Y una respuesta frecuente aún entre los eruditos, es la posibilidad que este fluido sea algo similar a un tóxico o veneno, con efectos no sólo personales o familiares sino de la comunidad entera.

Wellman, estudioso de las costumbres autóctonas de los indígenas norteamericanos, hace referencia de los indígenas Pomeroon Arawak, habitantes de las orillas del río Pomeroon en la Guyana, quienes apartaban a las mujeres menstruantes durante la comida para evitar que los demás miembros de la tribu se intoxicaran. ${ }^{49}$

Si un hombre se le acercaba en esos días corría peligro que sus pies se hincharan y al caminar las plantas se le podían quebrar por resequedad. El lector puede comparar la similitud entre estas creencias y las sentencias de la Sagrada Biblia Católica en su libro Levítico, mencionadas atrás.

En Santander, Colombia, muchas mujeres creen que darle a un hombre una bebida que contenga un poquito de sangre menstrual lo vuelve loco. Sin embargo, las creencias populares que percibían la sangre como un líquido tóxico, parecen tener ahora un soporte científico desde los reportes de Kamiyama y otros investigadores, que demostraron la presencia de endotoxinas bacterianas en el fluido menstrual de las mujeres infértiles. ${ }^{49}$ Estas endotoxinas parecen participar 
en algunos procesos anormales que culminan como una falla de la implantación, un aborto espontáneo o un parto prematuro. ${ }^{50}$

\section{CONSIDERACIONES FINALES}

Desde el comienzo de los tiempos la menstruación ha tenido un halo de misterio para la humanidad. No hay explicaciones satisfactorias aún hoy, del por qué las mujeres requieren este evento fisiológico para mantener la fertilidad, no necesario en otras especies de animales mamíferos. ${ }^{51}$

Las actitudes positivas y negativas hacia este proceso fisiológico ${ }^{52,53}$ perdurarán a través de los siglos. Las creencias mágicas recogidas por Plinio el Viejo 20 siglos atrás, se han transmitido de boca en boca, de padres a hijos y entre amigos, lo que hace suponer que seguirán su curso a través de las generaciones venideras, transmitidas por el lenguaje inmortal de la tradición oral, a pesar de que los avances de la ciencia expliquen satisfactoriamente los procesos fisiológicos y patológicos del cuerpo humano, y los fenómenos de la naturaleza. La gente del común seguirá creyendo en espíritus malos que transmiten enfermedades, y siempre habrá indios amazónicos, magos, astrólogos, espiritistas, etc., a quienes acudir para conseguir "la contra".

Algunas frases de los libros sagrados de las diferentes religiones se han utilizado en el pasado para discriminar y castigar a quienes han asumido determinadas conductas o han sido sospechosos de asumirlas. Dichos castigos han llegado al suplicio y la muerte. Es muy probable que en el futuro, la conjunción del poder religioso y político en manos de líderes fundamentalistas, sea utilizada de manera abusiva contra grupos humanos sometidos, y quizás las peores libradas sean, como siempre, las mujeres.

\section{REFERENCIAS}

1. Vox. Diccionario Latino-Español y Español-Latino. Barcelona: Edit. Bibliograf.; 1986.

2. Diccionario terminológico de ciencias médicas. Barcelona: Salvat editores; 1974.
3. Flórez L. Léxico del cuerpo humano en Colombia. Bogotá: Instituto Caro y Cuervo; 1969.

4. Beauvoir S. El Segundo Sexo. Buenos Aires: Edit. Sudamericana; 2002.

5. Strassmann BI. The evolution of endometrial cycles and menstruation. Q Rev Biol 1996;71:181-220.

6. Sellares Biel E, Mallorqui Ayuso N. The myth of menstruation and its social repercussions. The midwife's role in demystification. Rev Enferm 1981;5:19-24.

7. Buckey T, Gottlieb A. Blood magic: the anthropology of menstruation. Berkeley, CA: University of California Press; 1998.

8. Valdiserri RO. Menstruation and medical theory: an historical overview. J Am Med Womens Assoc 1983;38:66-70.

9. Datta B, Gupta D. The age of menarche in classical India. Ann Hum Biol 1981; 8:351-9.

10. Walker B. "Menstruation” in The Women's Encyclopedia of Myths and Secrets. New Jersey: Castle Books; 1983.

11. http://www.etniasdecolombia.org/periodico_detalle. asp?cid $=921$

12. Biblioteca Virtual Banco de la República, Colombia. Geografía Humana de Colombia. Región de la Orinoquía, Los U’Wa. Tomo III - Volúmen 2. Disponible en: http://www.banrep.gov.co/blaavirtual/letra-g/geogra32/uwa31.htm

13. Goodman D. Women's seclusion and men's honor: sex roles in North India, Bangladesh and Pakistan. Phoenix: University of Arizona Press; 1988.

14. http://www.etniasdecolombia.org/indigenas/wayu.asp

15. Andrews J, Digby A. Sex and Seclusion, Class and Custody. Perspectives on Gender and Class in the History of British and Irish Psychiatry. Amsterdam: Editions Rodopi V.B.; 2004.

16. Engineer AA (ed.). Status of Women in Islam. Delhi: Ajanta Publications; 1987. p. 38-41.

17. Hallak K, Hallak KM. El Corán Sagrado y la Traduccion de su sentido en lengua española (Spanish Qur'an with Arabic text) Betsville, MD: Amana Pubis; 1997.

18. Walther W. Women in Islam. New York: Markus Wiener Publishing Inc.; 1993.

19. Mernissi F. The Veil and the Male Elite. A Feminist Interpretation of Women's Rights in Islam. Trans. Lakeland MJ. New York: Addison-Wesley Publishing Company; 1992. 
20. Ahmed L. Women and Gender in Islam. Historical Roots of a Modern Debate. New Haven, CT: Yale University Press; 1992.

21. Sagrada Biblia. Versión castellana del Ilmo Sr. Torres Felix Amat. New York: Edit. Grolier; 1958. Libro levítico, capítulo XV. p. 113-14.

22. Ben-Noun LL. What is the biblical attitude towards personal hygiene during vaginal bleeding? Eur J Obstet Gynecol Reprod Biol 2003;106:99-101.

23. Selvidge MJ. "Mark 5:25-34 and Leviticus 15:19-20. A Reaction to Restrictive Purity Regulations”. J Bibl Lit 1984;103:619-24.

24. Schwarz D. Menstruation and the woman in Judaism. Zentralbl Gynakol 1988;110:970-4.

25. Antonelli JS. "Menstruation”. In: The Image of God. A Feminist Commentary on the Torah. London: Jason Aronson; 1995. p. 276-87.

26. Cohen SJD. Purity and Piety: The Separation of Menstruants from the Sancta. In: Grossman S, Haut R (eds.). Daughters of the King: Women and the Synagogue. New York: Jewish Publication Society; 1992. p. 103-15.

27. Camp C. A Female Initiation Rite in the Neigrie Area. In: Habel NC (ed.). Powers, Plumes, and Piglets: Phenomena of Melanesian Religion. Bedford Park, South Australia: Australian Association for the Study of Religions; 1979. p. 68-83.

28. Peters FE. The Menstruant. In: Judaism, Christianity, and Islam. The Classical Texts and Their Interpretation. Princeton: Edit. Princeton University Press; 1990. p. 731-34.

29. Opie IA, Tatem M. Menstruating Woman. In: A Dictionary of Superstitions. Oxford: Oxford University Press; 1989. p. 247.

30. O'Grady K. "Menstruation" in Women and World Religions. New York: Macmillan; 1999

31. Phipps WE. The Menstrual Taboo in the Judeo-Christian Tradition. J Relig Health 1980;19:298-303.

32- Carey S. Pliny's Catalogue of Culture. Art and Empire in the Natural History. New York: Oxford University Press Inc.; 2001.

33. Healy JF. Pliny the Elder on Science and Technology. London: Oxford University Press Inc.; 2000.

34. Marco Polo. El libro de Marco Polo. Las apostillas a la Historia Natural de Plinio el Viejo. Universidad de Sevilla; 1992.

35. Momoko T. "Menstruation Sutra Belief in Japan". Japanese J Relig Stud 1983;10:229-45.
36. Skibola CF. The effect of Fucus vesiculosus, an edible brown seaweed, upon menstrual cycle length and hormonal status in three pre-menopausal women: a case report. BMC Complement Altern Med 2004;4:10.

37. Backe J. Tainted femininity--traces of traditional menstruation myths in product advertising of feminine hygiene products. Gynakol Geburtshilfliche Rundsch 1997;37:30-8.

38. Bergqvist A. [Menstruation still full of myths]. Lakartidningen 1999 14;96:1860-76.

39. Bonnet-Cadilhac C. Translation and commentary of the Hippocrates treatise 'The illness of girls'. Hist Philos Life Sci 1993;15:147-63.

40. Backe J. History of menstruation--an aspect of the medical history of the woman. Gynakol Geburtshilfliche Rundsch 1996;36:201-7.

41. Delaney J, Lupton MJ, Toth E. The Course. A Cultural History of Menstruation. Springfield: University Illinois Press; 1988.

42. Ferro-Luzzi G. Food Avoidances at Puberty and Menstruation in Tamilnad: An Anthropological Study. In: Robson JRK (ed.). Food, Ecology and Culture. Readings in the Anthropology of Dietary Practices. New York: Gordon and Breach Science Publishers; 1980. p. 93-100.

43. Grahn J. Blood, bread and roses. How menstruation created the world. Washington: Beacon Press;1994.

44. Roberts SJ, Garling J. The menstrual myth revisited. Nurs Forum. 1981;20:267-73.

45. Finn CA. Why do women menstruate? Historical and evolutionary review. Eur J Obstet Gynecol Reprod Biol 1996;70:3-8.

46. Finn CA Why do women and some other primates menstruate? Perspect Biol Med 1987;30:566-74.

47. Finn CA. Menstruation: a nonadaptive consequence of uterine evolution. Q Rev Biol 1998;73:163-73.

48. Wellmann KF. Menstruation, pregnancy, and birth in prehistoric rock drawings of North America.Dtsch Med Wochenschr 1972;97:1670-1.

49. Kamiyama S, Teruya Y, Nohara M, Kanazawa K. Bacterial endotoxin in the endometrium and its clinical significance in reproduction. Fertil Steril 2004; 82:805.

50. Romero R, Espinosa J, Mazor M. Can endometrial infection/inflammation explain implantation failure, spontaneous abortion, and preterm birth after in vitro fertilization? Fertil Steril 2004;82:799-804. 
51. Lucrezio T. Historical considerations on the interpretation of the menstrual phenomenon from antiquity to our times. Atti Mem Accad Stor Arte Sanit 1966;32:103-8.

52. McPherson ME, Korfine L. Menstruation across time: menarche, menstrual attitudes, experiences, and behaviors. Womens Health Issues 2004;14:193-200.
53. Mansfield PK, Stubbs ML. Tracking the course of menstrual life: contributions from the Society for Menstrual Cycle Research. Womens Health Issues 2004;14:174-6.

Conflicto de intereses: ninguno declarado. 